\title{
Jetzt ist die beste Zeit
}

In der Einleitung des Buches habe ich Ihnen versprochen, dass Sie konkrete Handlungsempfehlungen für die zentralen Aufgaben als Führungskraft erhalten werden. Wir haben in den letzten Kapiteln gesehen, welche Fähigkeiten die Führungskraft der Zukunft in der IT haben muss, wie sie Kooperation und Innovation fördert sowie durch das Führen mit Zielen und Feedback ihre Mitarbeiter dabei unterstützt, ihre beste Leistung zu erbringen. Wir haben mit einigen Vorurteilen zu den jungen Generationen aufgeräumt und die Auswirkungen der selbsterfüllenden Prophezeiungen auf das gesamte Arbeitsumfeld in der IT besprochen.

Gibt es einen besseren Zeitpunkt Ihr Führungsverhalten zu verändern als jetzt?

Lassen Sie uns zur Beantwortung der Frage abschließend in den Hubschrauber steigen und aus dieser Perspektive auf die Zukunft der IT und Ihre Zukunft als Führungskraft blicken. 